\title{
THE WINTERING MERLINS OF SASKATOON
}

IAN G. WARKENTIN, Department of Zoological Research, National Zoological Park, Smithsonian Institution, Washington, D. C. 20008-2598

Traditionally, Merlins which breed in the northern Great Plains of North America (Richardson's Merlin, F. C. richardsonii) are migratory. Each fall, after completion of breeding, they migrate from this area to the southcentral United States and northern Mexico. The establishment of urbanbased Merlin populations, and the occurrence of some individuals from these populations remaining in the cities through the winter period (November through February), are recent phenomena. Although William Rowan (University of Alberta Archives) reported Merlins during the winter in Edmonton as early as 1922 , there were no other reports of wintering birds on the Prairies until $1948 .{ }^{11}$ Since that time however, wintering populations have developed in all major Canadian prairie cities, and many of the smaller urban centres. The establishment and growth of these populations is evident from analyses of the numbers of Merlins seen on annual Christmas Bird Counts (CBC's). The analyses indicate that in four major cities of the Canadian Great Plains (Edmonton and Calgary, Alberta, and Regina and Saskatoon, Saskatchewan) significant increases in the number of Merlins on CBC's occurred during the period from 1957 to $1983 .^{5}$ In contrast, the numbers of Merlins on CBC's in U.S. centres of the Great Plains region (considered more within the traditional winter range of Richardson's Merlin) remained steady over the same period. This suggests a northward expansion of the wintering range of Merlins to include these new wintering grounds, and a growing use of these areas which has continued to increase through to present. In Saskatoon, a substantial population of wintering Merlins was not established until the mid- to late $1960 \mathrm{~s}$, but since that time the population has greatly expanded. ${ }^{15}$

Along with the development of wintering populations in the cities of the northern Great Plains has come the establishment of breeding populations of Merlins in the same urban centres. Merlins wintered for a decade or more in communities across the prairies before they started breeding. In fact, the initial breeding colonization of towns and cities may have been made easier for Merlins by their habituation to people, gained while spending their winters in these urban centres. The best documentation of breeding population growth in an urban centre over time comes from a detailed study of the Saskatoon Merlin population, which has been monitored since its initiation in 1971. Each year the city has been searched to locate all Merlin pairs and to band both the chicks and breeding adults. In the 20 years since that first nest in 1971, the population grew to a high of 31 successfully breeding pairs. With a substantial winter population, Saskatoon proved to be an ideal location to study this unusual phenomenon.

The primary question is, "Why 


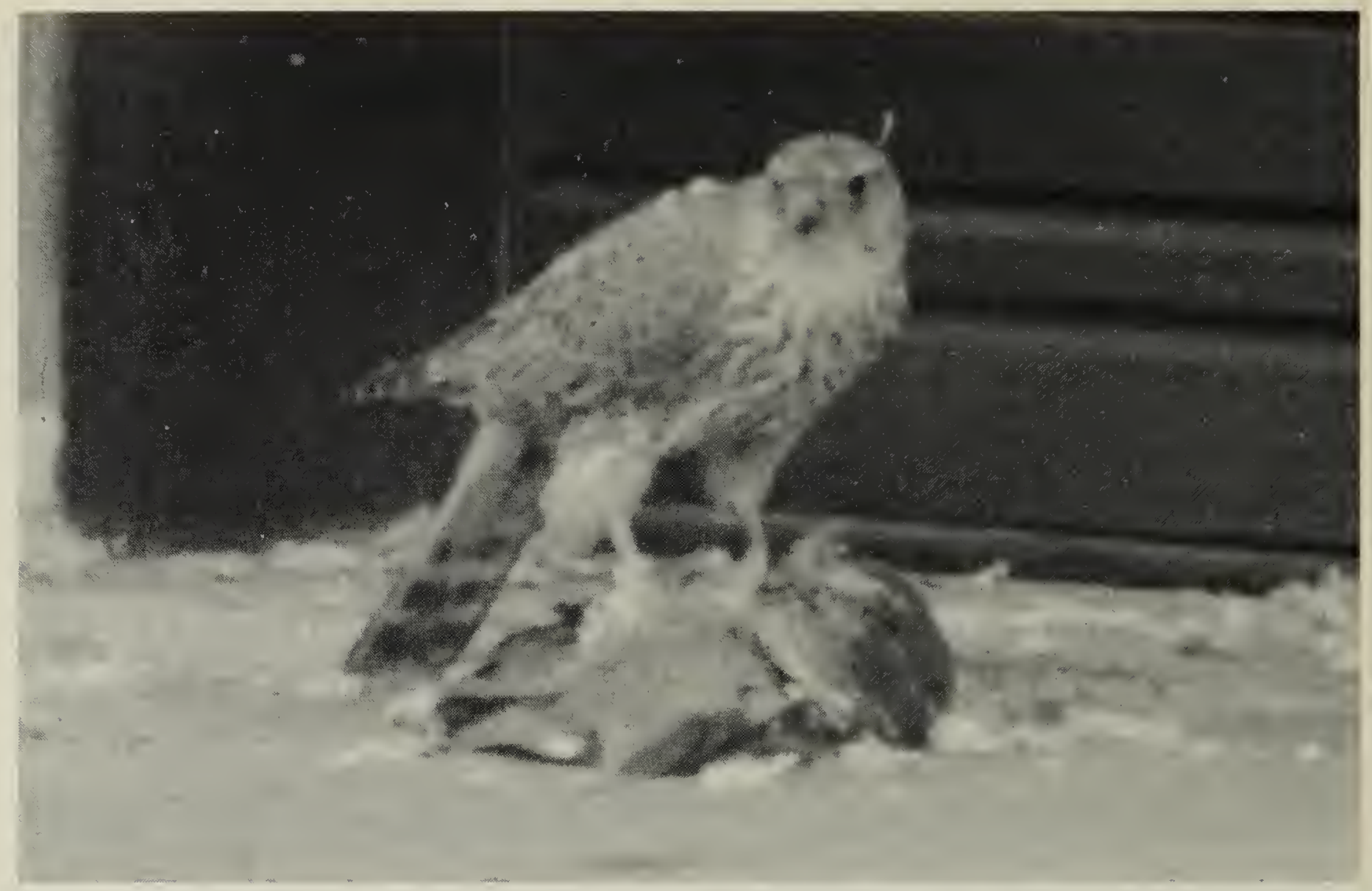

would a Merlin dramatically alter its behaviour from a strictly migratory to a non-migratory strategy?" - particularly when such a change means remaining through the winter in an urban centre where the climate can become quite harsh and potentially life-threatening if the proper resources are not available. While a precise answer to this question is elusive, the results of five winters (1983-84 through 1987-88) spent examining the Merlin population of Saskatoon may provide some clues as to what triggered the development of this new behaviour pattern in so many individuals. I believe that the key to understanding this phenomenon lies within the phrase above referring to the availability of appropriate resources.

\section{Prey Availability and Winter Diet} Obviously, because of their relative abilities to store energy for both short-term and long-term use, the consistency of food availability is more critical to small than to large birds. Species such as the Bald
Eagle wintering in this region are able to consume great quantities of food at one time and store large amounts of energy as fats which can be drawn upon for periods up to several weeks, if necessary, to survive through prolonged bad weather or food shortages. In contrast, smaller species such as the Black-capped Chickadee wintering in the same area are unable to store large quantities of energy and in extreme cold may survive only a day or two if unable to forage due to inclement weather. For a relatively largebodied bird such as the Merlin, consistency of food supply is not as critical; fat reserves could allow a Merlin in good condition to survive without feeding for four or five days in winter (pers. obs.). Thus, Merlins are well able to withstand periodic short-term food shortage (although shortages may be more serious in the long term).

One of the most important requirements for birds existing in cold climates, however, is abundant and 


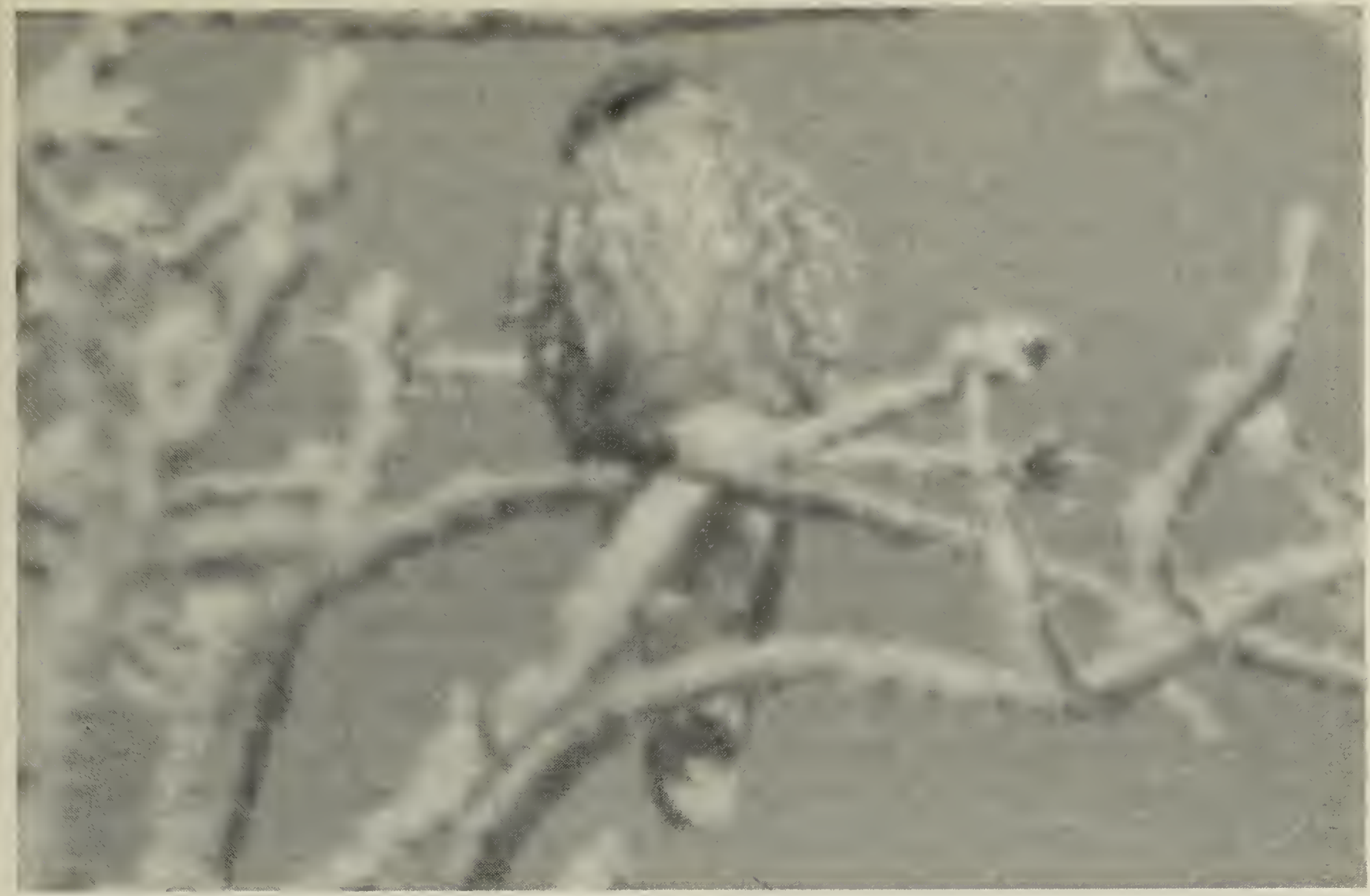

accessible food. Previous analyses of CBC's over a 27-year period found a positive correlation between the rise in Merlin numbers in the major cities of the northern Great Plains and increases in the numbers of Bohemian Waxwings seen. ${ }^{5}$ Although cause and effect cannot be separated in this type of statistical examination and a direct link between the two cannot be assumed, there is other evidence to support this link. During my study, waxwings were the prey being consumed on 23 of 133 $(17 \%)$ occasions when I encountered feeding Merlins. This translates to about $26 \%$ of the Merlin diet (by weight) when consideration is given to the sizes of all prey eaten during my observations. With over a quarter of the diet consisting of waxwings, there is the possibility of a link between increased numbers of waxwings in cities and increased Merlin populations. It is necessary to assume also that the diet of a typical Merlin has remained relatively unchanged since they first began wintering in Saskatoon.

By far the predominant prey of Merlins in Saskatoon in winter is the House Sparrow. This species constituted 96 of 133 (72\%) prey observed, or an estimated $66 \%$ of the diet by weight. These values are consistent with those found for the diet of Merlins breeding in Saskatoon in which House Sparrows comprised $64 \%$ and $67 \%$ (N. Sodhi, pers. comm.) of all prey individuals and $76 \%$ of prey at Merlin nests in Edmonton. Unlike the increasing numbers of waxwings seen over the years, the numbers of House Sparrows (seen on CBC's) showed no significant increase in the cities of the northern Great Plains during the period from 1957 to $1983 .{ }^{5}$ Given the large numbers of House Sparrows found in most of these cities, their high populations may be one reason for the initial attraction of Merlins to the city, although this may not explain the increase in Merlin populations over time. 
With conservative estimates putting the number of House Sparrows in Saskatoon in the tens of thousands each winter, and varying (but apparently increasing) numbers of Bohemian Waxwings, food for Merlins is abundant. However, prey must also be obtainable. Are those birds which spend the winter in Saskatoon able to capture prey in winter with similar efficiency to that of other Merlin populations? Only three other studies of wintering Merlins are available for comparison with my data. In California, a female Merlin was successful on $13 \%$ of 343 attempts to capture prey. ${ }^{10}$ Merlins hunting on estuaries in Washington, also on the Pacific coast, were successful in $22 \%$ of 111 attempts, and Merlins wintering in West Galloway, U.K., were successful on $10 \%$ of 114 attempts. ${ }^{1,2}$ Through the use of tailmounted radio transmitters, I observed Merlins in Saskatoon make 789 hunting attempts resulting in 102 kills ( $13 \%$ hunting success). Because this observation technique tends to favour the confirmation of kills and underestimate hunting attempts, this success rate may be biased upwards slightly, but it is certainly well within the range of what might be expected from the results of the other studies. Prey are imposing similar food constraints, through obtainability, on Merlins throughout their wintering range.

Another way to approach the question of prey abundance is to look at the energetic requirements of an individual. How much food (and thus how much energy) is needed to maintain bodily functions, body temperature, plus the costs of activities such as perching, flying, preening, eating and others? Using a technique called open-circuit respirometry, I measured the energetic costs of these factors in captive Merlins to develop daily energy budgets. ${ }^{17}$ Taking into account average weather conditions during winter in Saskatoon, and how this influences the amount of energy required to maintain body temperature, I translated all of these costs into the number of prey needed by each individual Merlin to survive the winter in the wild. I then extrapolated from this value to determine what would be needed for the population as a whole. Each Merlin requires nearly 200 House Sparrow-sized birds for the period from November through February. Based on a maximum population estimate obtained during this study of 38 Merlins present one winter, the overall consumption by Merlins in Saskatoon for the winter period would be $200 \mathrm{~kg}$ or nearly 7600 House Sparrow-sized prey. This figure is well below estimates of the potential prey population, indicating a more than sufficient food base for Merlins in Saskatoon.

Roost Availability In addition to a reliable food supply, wintering birds in harsh climates require suitable nighttime roost sites. Mills suggests that the winter range of the American Kestrel expanded in the Ohio River valley due to the construction, and later abandonment, of large wooden barns. ${ }^{7}$ These structures provided an abundance of sheltered roost sites enabling better winter survival in this region. Likewise, Merlins wintering in the cities of the northern Great Plains region require adequate protection from the elements at night roosts. This was not available until coniferous trees were planted and had grown large enough to provide sufficient shelter.

Along with providing cover overhead which limits the amount of body heat lost to the night sky, wind reduction makes roost availability an additional important factor to wintering birds. Other studies have shown that 
the energy savings for a bird in a protected roost are in the $5-10 \%$ range; that is, for each night when they use a protected roost, birds expend $5-10 \%$ less energy than birds roosting on an open (unprotected) perch. $^{12,18}$ In this study, I found that Merlins which use protected nighttime roosts saved about $6 \%$ of their daily energy budget compared with the theoretical costs of a bird roosting in the open, and most of this saving was due to sheltering from the wind. ${ }^{17}$ This could be seen in the behaviour of Merlins entering a roost tree: once perched on the selected tree, they slowly hopped from branch to branch around the tree near the trunk, finally settling on a lee-side branch, out of the wind and right next to the trunk. A brief study of the wind in and around four roosts revealed that the average wind reduction in the roost positions chosen was about $71 \%$.

All of the Merlin roosts discovered in Saskatoon were in coniferous trees, either White or Blue Spruce. Generally, they were found along residential streets or in backyards. Some were in parks, cemeteries and schoolyards. Various characteristics of these roost trees and the areas immediately surrounding them were compared with those same features in a sample of trees chosen at random from across the city. The characteristics of the area immediately surrounding the roost (such as the proximity of the nearest house, distance to the nearest available open perch or utility pole, distance to the nearest road, etc.) apparently had little influence on the selection of a particular tree. Analyses suggested that the features of the tree itself, particularly size, were most important to the Merlins. One Merlin roosted in a tree which was only $7 \mathrm{~m}$ tall, but the average roost tree was significantly taller than what was generally available in the city $(14.3 \mathrm{~m}$ for selected trees versus an average tree height among the random sample of $11.3 \mathrm{~m}$ ). The importance of tree size for a Merlin roost relates back to the amount of shelter from the wind a tree will provide to a roosting Merlin. A larger tree has more branches and needles to block the wind giving better protection to a Merlin than it would receive if perched in a smaller tree, or on an open perch such as a deciduous tree or power pole.

Both suitable roost sites and the availability of food were therefore probably essential components in the establishment of wintering Merlin populations in Saskatoon and other cities across the Prairies. But it is difficult to separate these two factors, or rank them in importance. In fact, there were likely conifers which would have been large enough to be suitable as roost sites many years before Merlins began to winter here. Likewise, a substantial House Sparrow population was present long before the establishment of a winter Merlin population. It is also unlikely that Merlins were initially attracted to the cities by the appearance of waxwings, since migratory Merlins leave the area long before the Bohemian Waxwings arrive from the north. These points do not address the question as to why these populations came about.

In all likelihood, chance and a strategy which proved to be successful played a large part in the development of Merlin populations across the northern Great Plains. Whether late migrating Merlins were "trapped" by early winter storms which then made it impossible to continue migrating south; or, as is more likely, birds migrating along the river systems of the Prairies (which are part of their traditional habitat) encoun- 
tered the above features in the cities, stayed for the winter and were successful, the strategy is now well established. There are at least two factors which would favour this new behaviour pattern. It would appear that it is better, if possible, to avoid the heavy energetic costs and potential dangers of migration such as human and other predators, hunting in unfamiliar terrain which presumably makes it more difficult, and increases both the chance of starvation as well as that of injuries such as flying into power lines (particularly among inexperienced birds). Remaining on, or near, the breeding grounds is also advantageous because it could lead to nonmigrant birds obtaining better nest sites (territories), and/or better quality mates by being the first ones there in spring. Despite the potential advantages to nonmigratory birds, these benefits must be weighed against the costs of surviving harsh and potentially life-threatening winters at northern latitudes.

\section{Composition of Wintering Popula-} tion Although the data are insufficient to examine differences in survivorship between migrant and nonmigrant birds, in this section I will look at another aspect of fitness and compare the productivity of birds in these two groups. When this project began in 1983, one of my first questions was, "Who are the birds wintering here, and what, if any, is their relationship to the breeding population?" There are several possible origins for the birds now wintering in Saskatoon. They could have been Richardson's Merlins breeding further north in the parkland region of the province, or in the countryside adjacent to Saskatoon. Another possibility was that they were the birds from the boreal forests of northern Saskatchewan (the subspecies F. C. columbarius), which stopped in the city on their way south and re- mained. By the time I started my study, they could also have been birds from the Saskatoon breeding population, or a combination of these groups. Because of the extensive program of banding Merlins in Saskatoon which has been going on since 1971, I was able to address this question directly. While it is possible that some birds are entering from the surrounding countryside for the winter, none of the birds seen during the five winters of this study were of the darker (boreal) columbarius subspecies. In fact, of 303 sightings where both legs of the birds could be seen, only 4 were confirmed to be unbanded. Because there are no other large-scale Merlin banding programs currently operating around Saskatoon, this means that in excess of $98 \%$ of the wintering Merlin population were hatched in the city, or had been banded as a breeding adult in Saskatoon.

By trapping individuals each winter, I also obtained a precise picture of the composition and size of the wintering population in terms of sex and age. ${ }^{15}$ I found that males and females were equally represented among the birds trapped. However, the distribution of ages within the sexes differed significantly. I found that most $(90 \%)$ of the 32 males caught in winter were less than four years old, and the majority $(53 \%)$ of 23 females were four years or older. The presence of relatively fewer younger females may reflect a lower survival rate among yearling females (birds hatched the preceding summer) in the harsh winter climate of Saskatoon. The yearling females caught in winter were much lighter than expected. On average they were $42 \mathrm{~g}$ less than wintering adult females (two+ years old) and $20 \mathrm{~g}$ less than the average of yearling females breeding in their first summer. For all other age/sex groups (i. e., 
yearling males, and adult males and females) average winter masses of nonmigrants were greater than their summer counterparts by $5-10 \%$. This suggested that yearling females wintering in Saskatoon were in much poorer condition and less likely to survive. This may be related to the slower development of hunting skills in yearling females which could make it more difficult for them to survive winters at northern latitudes than males.

The predominance among males of younger birds is interesting, since few of these birds (especially yearlings and two year olds) had been captured as breeders. The presence of young males (those that had not previously bred) in winter may reflect the level of competition among males for nest sites, and the eventual advantage of being on territory sooner in spring in order to obtain the chance to breed. Although migrant yearlings enter the breeding population at levels similar to nonmigrant yearling birds, among those birds which enter the breeding population as second-year birds, a higher proportion of nonmigrant birds were successful in obtaining a breeding site. Thus, despite the potentially heavy cost to survive through winter in Saskatoon, nonmigrants eventually obtain proportionately more chances to breed.

Trapping also enabled me to estimate the number of Merlins in Saskatoon each winter. I used a technique of marking birds with plastic leg streamers that allowed them to be identified from a distance. The number of Merlins seen which had been marked was then compared with the number seen which were not marked. In total, I caught and marked 45 Merlins, 37 of which had been banded as chicks, and were of known age, while 8 had been banded as breeding adults. Nine were seen in more than one winter. Population estimates for Merlins wintering in Saskatoon varied from 22 to 38 birds. Although the number of adults seen each winter remained constant (estimated between 16 and 20 individuals), the estimated number of yearlings fluctuated from 3 to 22 birds and was the primary cause of overall population fluctuations. Why the number of yearlings wintering in Saskatoon varied so greatly from year to year is still a mystery.

An interesting insight was gained by examining the parentage of those birds trapped in winter. Of the 20 birds trapped for which I knew the parents, 19 had at least one parent who had also been trapped in the city as a wintering bird. I also looked at the parentage of birds which returned to breed in the city but had not been captured in winter (and hence were presumed to be migrants). Only 4 of 13 presumed migrants had at least one nonmigrant parent, which was significantly different from the value for nonmigrant birds. Thus, it appears that there is some inherited component in the tendency to remain in Saskatoon as a wintering bird which is passed down to the offspring of nonmigrant birds. If the trend continues, this could have a substantial impact on future Merlin populations leading to a subpopulation of Merlins which is strictly resident in the cities of the northern Great Plains. However, at this point, they are apparently not isolated enough from migrant populations. There is also no evidence that mates are chosen based on their migratory strategy and, with the continued input of genetic material from presumed migrants, at present it is difficult to see a separation between distinct resident urban and migrant rural populations. 
We now know that the population of wintering Merlins in Saskatoon is composed of males and females in relatively equal numbers, with more younger males than older males and conversely fewer younger females than older females. I looked at the parentage of both nonmigrant and migrant birds, but moving forward to their ofispring can also be informative in terms of determining the advantages of being nonmigratory. One means of addressing this is to look at the number of offspring nonmigrant birds compared to the number produced by presumably migrant individuals. Twenty of the 45 Merlins I trapped in winter subsequently bred in the city. Comparing the average number of young produced in the nests of nonmigrant males with that of nests with a presumed migrant male (regardless of whether the female is a migrant or nonmigrant bird) revealed that more young were produced in the former than the latter. This raises the related question of what is gained among males by not migrating, and how this might relate to more young being produced. Presumably, year round residency enables nonmigrants to be on territory sooner than migrants, occupying the preferred or best quality sites first. I saw Merlins moving from wintering areas in the city' to new nesting areas in late winter (February - March) and some courtship activity occurring as early as the first week of February. Since migrant birds do not begin to arrive until late March most years, there is a substantial difference in when members of these two groups can be on the territory they chose for the following breeding season.

Nonmigrant birds are also likely to be more familiar with an area than their migrant counterparts, which would be particularly beneficial to males, who do all the hunting for a pair and their offspring from the courtship through to the second week of the nestling period. This familiarity may make them more efficient at exploiting the resources in their territory, which may in turn allow either an increase in the number of young produced, or the production of better quality chicks. The absence of a similar benefit to nonmigrant females may reflect the apparent lack of mate selection favouring the pairing of nonmigrant birds, as well as the differences in their roles during reproduction. Since the female does little hunting until later on in the breeding cycle, familiarity with an area may not be as important.

\section{Merlins Wintering in the City} Habitat How do wintering Merlins use the various habitat types in the city? How does this relate to the location of their breeding sites? As mentioned earlier, part of this study was based on monitoring the movements of Merlins equipped with radio transmitters. $^{16}$ Selected individuals were fitted with 4-g, battery-powered transmitters which broadcasted a signal that could be picked up by specialized receiving equipment. This technique (radio telemetry) allowed me to maintain contact with individual Merlins (often visually) as they moved about their home ranges in the city. The transmitters are small enough, and attached in such a way to the tail feathers, to minimize any impact on the bird and its behaviour.

Winter home ranges for eight birds followed during the study varied from 9 to 40 ha with an average size of 19 ha ( 1 ha $=10,000 \mathrm{~m}^{2}$ or 2.5 acres). Adult birds which had bred in Saskatoon the previous summer had much closer ties to their old territories of the past than yearling birds to their natal nest site. While none of the three yearlings had winter home ranges that included their natal site, 
the home ranges of four of seven adults contained their last nest site and all four of these had one frequently used nighttime roost within $100 \mathrm{~m}$ of their old nest. Over $90 \%$ of nests found between 1985 and 1987 were in the oldest habitat types occupied by Merlins (built prior to 1945 , or those from 1945 to 1960$).{ }^{13}$ So, just as their nest sites focus Merlin activity on older residential areas of Saskatoon, their winter activities are also centred on these areas to a large exteint. However, unlike a nest site during the breeding season, the nighttime roost of a wintering Merlin does not appear to be a focal point for activity. Although it appears that adults are likely to have a small number of frequently used roosts, the consistency of return to one roost varies from using a main roost $26 \%$ to $100 \%$ of the time.

There were distinct differences in the use of habitat types by adults and yearlings. While adults used mostly residential areas of the city built prior to 1960, yearlings also made frequent use of areas built as late as 1970. Both groups avoided use of the newest neighbourhoods in the city which is likely related to the lack of perching places - these areas are relatively devoid of trees and lack utility poles. Both groups also made extensive use of CommercialIndustrial habitat in the city, focusing on places like railyards, and seedcleaning plants, which are areas with high concentrations of House Sparrows. This is the habitat in which Merlins made nearly $50 \%$ of their hunting attempts. Among residential areas, the oldest habitats have the highest densities of House Sparrows, which may also help to explain the heavier use of these areas, but more likely (especially for adults) the heavy use of the two oldest habitats again relates back to the occupation (or defense) of a previously held nesting territory. It could also be expected that having spent a summer in one area, these birds are likely more familiar with the area and are more successful hunters because of this familiarity. Considering that some nests were as close as $100 \mathrm{~m}$, and breeding birds tend to remain close to their old nest through the next winter, there was also a great deal of overlap in winter home ranges. This occurred especially among birds which had been paired the previous summer, but also among apparently unrelated individuals. As many as three different birds have used the same prominent perch within the space of several hours. It appears that the areas occupied by Merlins in winter are not exclusively held, or defended, from other Merlins.

An unexpected aspect of Merlin habitat use during winter was their departure from the city to hunt in the surrounding countryside in farmyards and feedlots as far as $15 \mathrm{~km}$ away. Some travelled out for the entire day, but most went out and returned within several hours in the morning, repeating the pattern in the afternoon. These Merlins always returned to the city by dark. Four of five adults and one of three yearlings made use of the countryside in this way, suggesting that it may be something that is learned in the first or second year. One explanation for leaving the abundant food supply of the city is the very high density of House Sparrows found in these isolated locations across the countryside. There were also differences in the level of hunting success associated with rural and urban hunting attempts. Average hunting success was $14 \%$ in the city, but a substantially better $31 \%$ for birds hunting in the country. This difference may be a reflection of the extent of exposure among House Sparrows in these areas to Merlin at- 
tacks. In the countryside there are fewer avian predators in winter and these prey may have been exposed to fewer attacks, be less familiar with Merlins, and perhaps less vigilant than birds in the city.

Closing Remarks This study has revealed how it is possible for Merlins to inhabit cities on the northern Great Plains. It has also provided potential answers as to why some Merlins have undergone such a dramatic change in their behaviour, from being strictly migratory to remaining in this region through the year. However, this is only a first step towards gaining a better understanding of this behaviour and more work is necessary.

The northward movement of wintering ranges has been noted for a number of different species now, and with the continued acceleration of global warming this is a trend which is likely to continue. With time, more resident populations of Merlins will be established in towns and cities across the northern Great Plains, provided that the required resources are available. Whether this behaviour can be linked to changes in climate, is a matter for discussion. My feeling is that, given a stable climate over the last 100 years, these populations would still have developed. What was lacking previously, and perhaps was not discovered by the Merlins for some time after it became available, was the abundance of both food and suitable roosting sites, which I believe were critical to the beginning of these populations. This is not to say that such warming has not had, or will not have, an impact on Merlins. A warmer winter would be less demanding energetically for those individuals which did stay. This could lead to higher survival rates within these populations and ulti- mately change them. One potential impact is among yearling females whose survival rates at present appear to be very low in winter. If a greater proportion survive and remain in the city to breed, this could influence the genetic background of the population. At present, most females breeding in Saskatoon are from areas outside the city. ${ }^{6}$ If wintering females are more likely to survive and subsequently breed in the city, this could strengthen the development of an "urban" subpopulation, particularly if there is any selection favouring the pairing of nonmigrant birds.

Although quiet and unobtrusive in winter, Merlins are not secretive in the urban habitat and can be easily observed. They add a colourful and exciting component to the avian populations in these cities, completing the food chain. This gives people the opportunity to observe a complete, albeit simple, ecosystem right in their own backyard.

Acknowledgements Lynn Oliphant and Paul James contributed to this study in many ways. Financial support was provided by the Natural Sciences and Engineering Research Council of Canada (NSERC), the Canadian Wildlife Service University Research Support Fund, the Frank M. Chapman Memorial Fund of the American Museum of Natural History, the Canadian Plains Research Center, and the University of Saskatchewan. The manuscript was prepared while I held a NSERC Postdoctoral Fellowship; Daniel Hernandez of Museo Nacional de Costa Rica, San Jose, provided access to word processing facilities. Thanks to Jamie Doyle for reading an earlier version of the manuscript.

1. BUCHANAN, J.B., C.T. SCHICK, L. A. BRENNAN, and S.G. HERMAN. 
1988. Merlin predation on wintering Dunlins: hunting success and Dunlin escape tactics. Wilson Bull. 100:108118.

2. DICKSON, R. C. 1988 . Habitat preferences and prey of Merlins in winter. British Birds 81:269-274.

3. HOUSTON, C.S. and A. SCHMIDT. 1981. History of Richardson's Merlin in Saskatchewan. Blue Jay 39:30-37.

4. JAMES, P.C., and A.R. SMITH. 1987. Food habits of urban nesting Merlins, Falco columbarius, in Edmonton and Fort Saskatchewan, Alberta. Can. Field-Natur. 101:592-594.

5. JAMES, P.C., A.R. SMITH, L.W. OLIPHANT, and I. G. WARKENTIN. 1987. Northward expansion of the wintering range of Richardson's Merlin. J. Field Ornithol. 58:112-117.

6. JAMES, P.C., I.G. WARKENTIN, and L.W. OLIPHANT. 1989. Turnover and dispersal in urban Merlins (Falco columbarius). Ibis 131:426-429.

7. MILLS, G.S. 1975. A winter population study of the American Kestrel in central Ohio. Wilson Bull. 87:241-247.

8. OLIPHANT, L.W. 1974. Merlins, the Saskatoon falcons. Blue Jay 32:140147.

9. OLIPHANT, L.W. and S. MCTAGGART. 1977. Prey utilized by urban Merlins. Can. Field-Natur. 91:190192.

10.
PAGE, G. and D.F. WHITACRE. 1975. Raptor predation on wintering shorebirds. Condor 77:73-83.

11. ROY, J.F. 1956. Wintering Pigeon Hawks. Blue Jay 14:50.

12. WALSBERG, G.E. 1986. Thermal consequences of roost-site selection: the relative importance of three modes of heat conservation. Auk 103:1-7.

13. WARKENTIN, I.G. and P.C. JAMES. 1988. Nest-site selection by urban Merlins. Condor 90:734-738.

14. - 1990. Winter roost-site selection by urban Merlins (Falco columbarius). J. of Raptor Research 24:5-11.

15. WARKENTIN, I.G., P.C. JAMES and L.W. OLIPHANT. 1990. Body morphometrics, age structure, and partial migration of urban Merlins. Auk 107:25-34.

16. WARKENTIN, I.G. and L.W. OLIPHANT. 1990. Habitat use and foraging behaviour of urban Merlins (Falco columbarius) in winter. J. of Zool., London 221:539-563.

17. WARKENTIN, I.G. and N.H. WEST. 1990. Ecological energetics of wintering Merlins (Falco columbarius). Physiological Zool. 63:308-333.

18. WEBB, D.R. and C.M. ROGERS. 1988. Nocturnal energy expenditure of Dark-eyed Juncos roosting in Indiana during winter. Condor 90:107112.

"The music of the night insects has been familiar to every generation of men since the earliest humans; it has come down like a Greek chorus chanting around the actors throughout the course of human history." By Edwin Way Teale. Frank Graham, Jr., Audubon Jan-Feb/92. 